\title{
INTERVENÇÃO DOS AGENTES IMOBILIÁRIOS NO ENTORNO IMEDIATO DAS CENTRALIDADES DE RONDONÓPOLIS-MT
}

\author{
Ana Claudia Reis Bittencourt $\mathrm{t}^{\mathrm{i}}$ \\ Adinael Jr. Pereira da Trindade ${ }^{\mathrm{ii}}$ \\ Antonia Marilia Medeiros Nardesiii
}

\begin{abstract}
Resumo: o presente estudo teve como objetivo analisar a intervenção dos agentes imobiliários no entorno imediato das centralidades na cidade de Rondonópolis, estado de Mato Grosso. Para alcançar tal objetivo, identificamos as áreas de intervenção dos agentes imobiliários no entorno das centralidades, em seguida, caracterizamos a atuação dos mesmos na expansão do tecido urbano e por fim, mapeamos as áreas de maior especulação imobiliária. Tais mapeamentos foram feitos por intermédio do Google Earth. Para a concretização da pesquisa, fomos a campo para coletar, levantar e analisar os dados obtidos. Os dados obtidos permitiram-nos lançar um novo olhar sobre a expansão recente da cidade de Rondonópolis. Embora as áreas analisadas não sejam necessariamente "novas" quanto sua integração, na malha urbana essas áreas têm desempenhado diferentes papéis e funções quanto a seus usos e sua ligação com o modo de exploração capitalista.

Palavras-chave: centralidades; especulação imobiliária; expansão urbana; agentes imobiliários; áreas de intervenção.
\end{abstract}

\section{INTERVENTION OF REAL ESTATE AGENTS IN THE IMMEDIATE SURROUNDINGS OF RONDONÓPOLIS- MT CENTRALITIES}

\begin{abstract}
: the present study aimed to analyze the performance of real estate agents in the immediate surroundings of the centralities in the city of Rondonópolis, state of Mato Grosso. To achieve this goal, we identified the areas of intervention of real estate agents in the vicinity of the centralities, then we characterized their performance in the expansion of the urban fabric and finally, we map the areas of greater real estate speculation. Such mappings were made through Google
\end{abstract}

\footnotetext{
' Pós-Graduada em Atendimento Educacional Especializado e Psicomotricidade pela Instituição Faveni. Graduada em Biblioteconomia pela Universidade Federal de Mato Grosso (UFMT). Estudante de letras pela Universidade Federal de Rondonópolis. ORCID: https://orcid.org/0000-0001-8082-3637. E-mail: anabitt_gga@hotmail.com.

i'Mestrado em Geografia no Programa de Pós Graduação em Geografia da Universidade Federal de Mato Grosso.Especialização em Gestão Pública pela UFMT/CUR. Graduação em História pela UFMT/CUR. Feche de gabinete da Reitoria da UFR. ORCID: https://orcid.org/0000-0002-9078-3082. E-mail: adinaelgga@hotmail.com.

iii Doutora em Geografia pela Universidade de São Carlos. Professora adjunta do curso de Geografia da Universidade Federal de Rondonópolis. Vice-Reitora da Universidade Federal de Rondonópolis. ORCID: https://orcid.org/0000-0002-4992-6459. E-mail: amnarde@yahoo.com.br.
} 
Earth. To carry out the research, we went to the field to collect, collect and analyze the data obtained. The data obtained allowed us to take a new look at the recent expansion of the city of Rondonópolis. Although the areas analyzed are not necessarily "new" in terms of their integration, in the urban fabric these areas have played different roles and functions in terms of their uses and their connection with the mode of capitalist exploitation.

Keywords: centralities; real estate speculation; urban expansion; real estate agents; intervention areas.

\section{INTERVENCIÓN DE AGENTES INMOBILIARIOS EN EL ENTORNO INMEDIATO DE RONDONÓPOLIS-MT CENTRALIDADES}

Resumen: el presente estudio tuvo como objetivo analizar el desempeño de los agentes inmobiliarios en el entorno inmediato de las centralidades de la ciudad de Rondonópolis, estado de Mato Grosso. Para lograr este objetivo, identificamos las áreas de intervención de los agentes inmobiliarios en el entorno de las centralidades, luego caracterizamos su desempeño en la expansión del tejido urbano y finalmente, mapeamos las áreas de mayor especulación inmobiliaria. Estos mapeos se realizaron a través de Google Earth. Para llevar a cabo la investigación, nos dirigimos al campo para recolectar, recolectar y analizar los datos obtenidos. Los datos obtenidos nos permitieron dar una nueva mirada a la reciente expansión de la ciudad de Rondonópolis. Si bien las áreas analizadas no son necesariamente "nuevas" en cuanto a su integración, en el tejido urbano estas áreas han jugado roles y funciones diferentes en cuanto a sus usos y su conexión con el modo de explotación capitalista. Palabras clave: centralidades; especulación inmobiliaria; expansión urbana; agentes de bienes raíces; áreas de intervención.

\section{Introdução}

A produção da cidade tem sido ao longo do tempo fruto de diversos processos, originados em diferentes usos e motivações. Tivemos no passado as cidades-estados, cidades fortalezas, cidades portos, entrepostos comerciais, centros religiosos, entre outras.

Bittencourt; Trindade; Nardes, Intervenção dos Agentes Imobiliários no Entorno Imediato das Centralidades de Rondonópolis-MT DOI: https://doi.org/10.51308/continentes.v1i18.296 
A partir da revolução industrial e o advento do capitalismo, a cidade assumiu uma nova forma e função social. A partir desse fato, a cidade torna-se lócus principal da produção capitalista e o solo urbano converteu-se em mercadoria.

Esse novo paradigma acrescentou novos agentes na produção do espaço urbano e representou um novo olhar sobre a cidade que passou a ser vista como mercadoria em si mesma. Tal fenômeno, se expressa nos novos modos de exploração do solo urbano com a criação de novas áreas de interesse em torno das quais, surgem novos empreendimentos imobiliários destinados a diferentes públicos, com diferentes usos em decorrência das especificidades do solo urbano, surgida com vista a atender as necessidades de agentes sociais envolvidos no processo de ocupação.

Nesse estudo, procuramos identificar as áreas de interesses caracterizadas como centralidades na cidade de Rondonópolis, bem como a ação dos agentes e do capital imobiliário no entorno das áreas identificadas e seus impactos na expansão da malha urbana.

Desse modo, pretendemos analisar a atuação de agentes públicos e privados na produção das centralidades, bem como as estratégias de atuação dos agentes imobiliários no parcelamento, valorização e comércio do solo urbano com vista à obtenção de lucros que não raramente se convertem em um tipo de mais-valia.

A fim de alcançar tais objetivos, realizamos uma pesquisa bibliográfica em materiais físicos e on-line como livros, teses, artigos e outros materiais com o intuito de encontrar uma base teórica/metodológica acerca do tema proposto.

Também realizamos trabalho de campo para coleta e levantamento de dados com o propósito analisar os equipamentos urbanos e, a partir disso, elaboramos mapas temáticos que nos permitiram localizar as áreas de maior especulação imobiliária dentro dos recortes propostos.

Para uma melhor visualização do presente estudo, estruturamos o artigo do seguinte modo: Introdução, onde consta a trajetória da pesquisa; em seguida uma discussão acerca das centralidades e a expansão urbana; posteriormente, explanamos sobre a 
caracterização da atuação dos agentes imobiliários na expansão do tecido urbano e por fim, apresentamos as considerações finais.

\section{Centralidade e Expansão Urbana}

O processo de urbanização moderno que pode ser considerado decorrente do desenvolvimento de expansão do capitalismo, implicou a criação de novos paradigmas em relação à concepção de cidade e reprodução do espaço urbano. A cidade antes local de comércio, torna-se agora lócus privilegiado também da produção capitalista, centro de convergência das forças que regem a produção e consumo deste novo sistema de produção.

Nesse sentido, embora a transformação da cidade em urbana não tenha sido o processo linear, tendo ocorrido em diferentes tempos e sido influenciada por diversos fatores, a transformação da natureza da cidade outrora meramente citadina em urbana tem na revolução industrial talvez o fator mais proeminente. Conforme afirma TRINDADE (2017),

\footnotetext{
à medida que foi introduzido nesse espaço de poder e de comércio, as condições gerais de produção, com destaques à reprodução da força de trabalho, [...] a introdução da indústria na cidade, modificou a natureza do espaço transformando em urbano, não mais em contraposição ao campo, mas como continuum (TRINDADE, 2017: 28, grifo nosso).
}

A partir do novo paradigma apresentado pela revolução industrial, que consolida a capitalismo como doutrina econômica e social "regente da sociedade contemporânea" a cidade adquiri o status de mercadoria e o solo urbano torna-se um ativo econômico a ser explorado. Tal fenômeno produziu marcas na configuração do 
espaço urbano em função das relações sociais que nele se estabelecem. Nesse sentido, segundo SANTOS (1978),

\begin{abstract}
o espaço por suas características e por seu funcionamento, pelo que ele oferece a alguns e recusa a outros, pela seleção de localização feita entre as atividades e entre os homens, é o resultado de uma práxis coletiva que reproduz as relações sociais, [...] o espaço evolui pelo movimento da sociedade total (SANTOS, 1978: 171).
\end{abstract}

Dessa forma, a cidade moderna diferencia-se da cidade antiga e medieval por sua função e forma. Se antes a cidade era fortificada, amuralhada, a demanda por novos espaços tornou-a acessível, expansiva, sempre apta a incorporar novos espaços ao tecido urbano.

Contudo, o processo de exploração mercadológica do solo urbano também é responsável pelo processo de crescimento ora planejado e consciente, ora excludente e "desordenado" (sob o ponto de vista do planejamento do tecido urbano, conforme as normas do estatuto das cidades e/ou dos planos diretores das cidades). Dentre as características desse processo, podemos notar o surgimento de novas centralidades que podem estabelecer uma relação de oposição ou complementaridade no tocante ao centro original.

Neste sentido, MOTTER e BATELLA (2013: 2) afirmam que "com a recente expansão das cidades e o aumento da mobilidade adquirida pelos cidadãos, assistimos cada vez mais uma perda do papel comercial do centro". Castells (1983: 321) considerando o solo urbano um meio econômico, discorre que "a desconcentração da função comercial conduz à criação de centros-de-troca periféricos, servindo às áreas urbanas determinadas ou aproveitando-se de uma situação na rede de fluxos cotidianos na metrópole".

Bittencourt; Trindade; Nardes, Intervenção dos Agentes Imobiliários no Entorno Imediato das 
Sobre a constituição das centralidades, SILVA (2003), faz uma interessante reflexão sobre a origem/surgimento das centralidades a partir dos estudos de JOHNSON (1974), que ele sintetiza do seguinte modo:

a) O primeiro modelo apresentado foi o das "Áreas Concêntricas" formuladas por Burgess, em 1923, cuja organização espacial tinha como fundamental a consolidação do CBD urbano (Central Business District), o centro de negócios, e este seria circundado por áreas industriais de transição, em seguida por áreas de moradia operária e posteriormente de moradia burguesa;

b) A segunda teoria/modelo, apresentada pelo autor é a "Teoria Setorial", criada por Hoyt em 1939, sendo considerada um "aperfeiçoamento" da teoria das áreas concêntricas, pois também dispensava fundamental importância ao CBD urbano, como agente centralizador, mas acrescentaria o uso industrial que não se "encaixava" na teoria anterior;

c) A terceira teoria/modelo exposta, é a dos "Núcleos Múltiplos", formulada por Harris e Ullman, considerada mais complexa que as anteriores por aceitar a existência de centros secundários espacializados pela cidade. Johnson (1974) ainda chega a afirmar que esta contemplava aspectos sociais, econômicos e históricos das cidades e cita como exemplo o caso da cidade de Londres, que teria constituído sua área mais importante dos negócios sobre a cidade medieval (SILVA, 2003: 25-26, grifo nosso).

Neste sentido, embora corroboremos a crítica apresentada por SILVA (2003) acerca das generalizações a que se pretendem as referidas escolas, uma vez que produção/reprodução do espaço agrega elementos que extrapolam as explicações propostas por qualquer modelo predeterminado.

O fato gerador destas novas centralidades pode ser espontâneo, frutos do processo de exclusão social que segrega a população socialmente vulnerável, afastando ou dificultando o acesso aos produtos e serviços oferecidos no centro principal, favorecendo o surgimento de uma atividade comercial e/ou de serviço em localidades distintas que passam a atender um entorno maior vindo a constituir uma nova centralidade.

Bittencourt; Trindade; Nardes, Intervenção dos Agentes Imobiliários no Entorno Imediato das Centralidades de Rondonópolis-MT DOI: https://doi.org/10.51308/continentes.v1i18.296 
Outros tipos de centralidades podem também ser instituídos por agentes públicos ou privados que se dedicam a oferta de produtos e/ou serviços especializados, que uma vez consolidados tornam-se centralidades que exercem atração social, valorizam o entorno e capacitam tais áreas a serem exploradas como mercadorias no contexto da exploração capitalista.

Dessa forma, defendemos que o surgimento de novas centralidades no tecido urbano em completação ou contraposição ao centro principal possa ser explicado somente por uma teoria sócio-histórica, que contemplem também aspectos econômicos e espaciais como a dificuldade e custo da mobilidade urbana e as oportunidades por ela gerada quanto a ofertas de produtos e serviços que levam a formação de novos centros em condições específicas, como é o caso de Vila Operária que não obstante sua condição de distrito pleiteou por muito tempo sua independência político-administrativa em relação a Rondonópolis/MT.

Em todo caso, a existência da centralidade promove uma valorização do solo urbano, favorecendo sua exploração que pode assumir diversas formas, como a venda ou aluguel, além de estimular a especulação imobiliária. Nesse sentido, CAMPOS e SILVEIRA (2014) defendem que

A dinâmica de urbanização das cidades médias tem apresentado, nos últimos vinte anos, um processo intenso e desigual de valorização do solo associado à crescente promoção de novos produtos imobiliários (condomínios e loteamentos fechados) cuja instalação no espaço urbano tem sido acompanhada por mudanças na forma de produção do espaço urbano e da estruturação das cidades. Os efeitos desses processos sobre a organização espacial das cidades revelam momentos e formas distintas de articulação dos agentes produtores da cidade (CAMPOS; SILVEIRA, 2014: 15).

Nesta pesquisa, identificamos em Rondonópolis exemplos de ambos os processos, a título de exemplificação podemos citar a "área central" da Vila Operária (Imagem 1), localidade cuja origem decorre de um agrupamento formado por trabalhadores 
(operários) estabelecidos numa área que a época situava-se relativamente distante do centro político e econômico da cidade, na qual surgiu centro comercial (hoje consolidado), que atende à demanda de todo o entorno com ofertas de produtos e serviços.

Imagem 1: Centralidade - Vila Operária

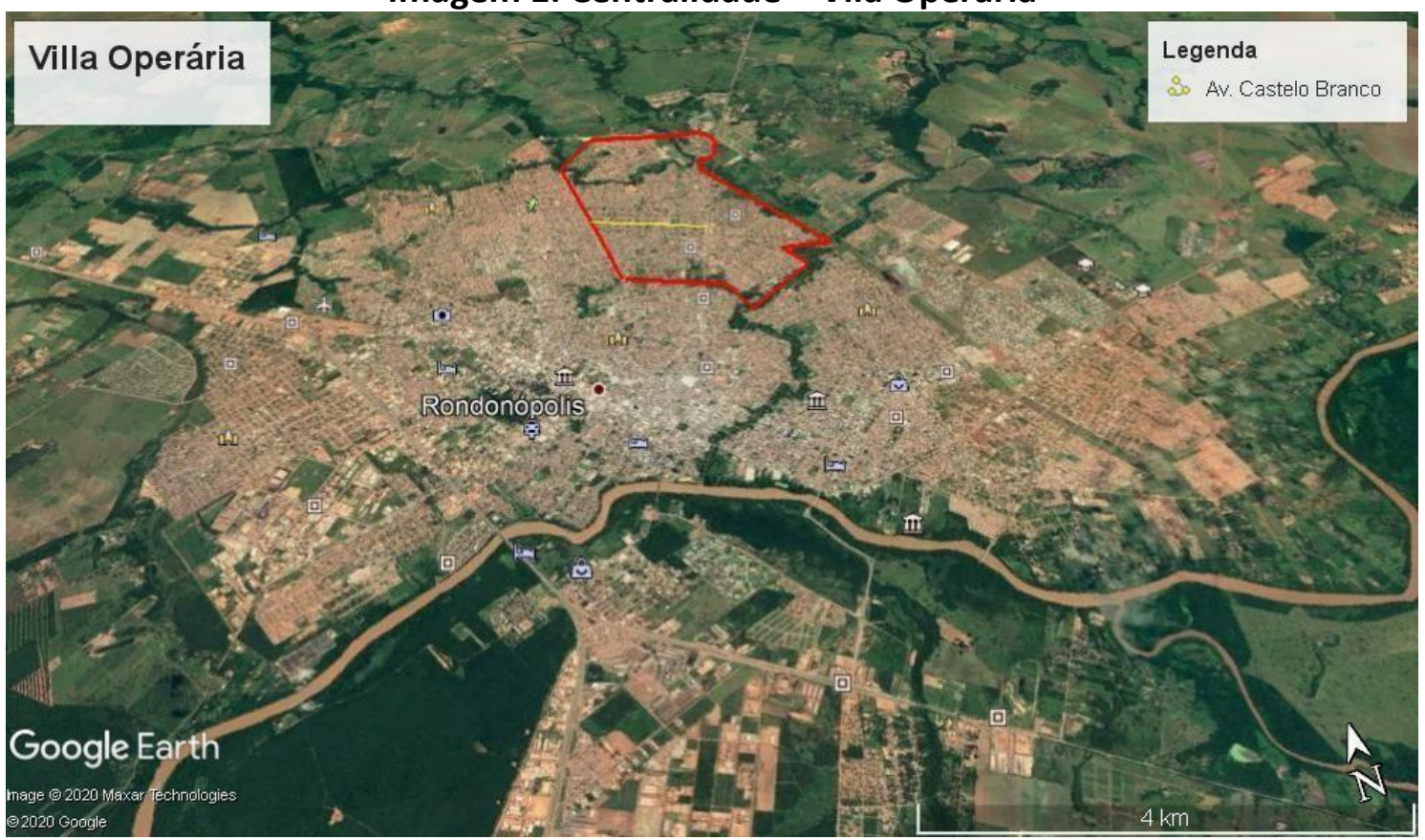

Fonte: Google Earth (Org. TRINDADE, Adinael Jr. Pereira).

A centralidade surgida em Vila Operária, mais especificamente na região da Avenida Castelo Branco, é decorrente de uma demanda reprimida existente na região. $\mathrm{O}$ acesso dos moradores aos produtos e serviços ofertados na região central eram dificultados pela distância e pela inexistência de um sistema adequado de mobilidade urbana. Tal demanda, passou a ser atendida localmente por pequenos empreendimentos, focados em gêneros de primeira necessidade que se expandiram no decorrer do tempo e 
ampliaram a oferta de produtos e serviços, vindo a consolidar-se como uma importante centralidade em Rondonópolis.

Paralelo a este processo, temos a região compreendida pela confluência das avenidas Júlio Campos e a Universidade Federal de Rondonópolis, (Foto 1) na qual notamos um processo orientado por um esforço sensibilizado dos agentes imobiliários, que por meio da instalação de equipamentos estimularam o surgimento de nova centralidades. Dentre estes, destacamos o shopping Rondon Plaza e a Universidade Federal.
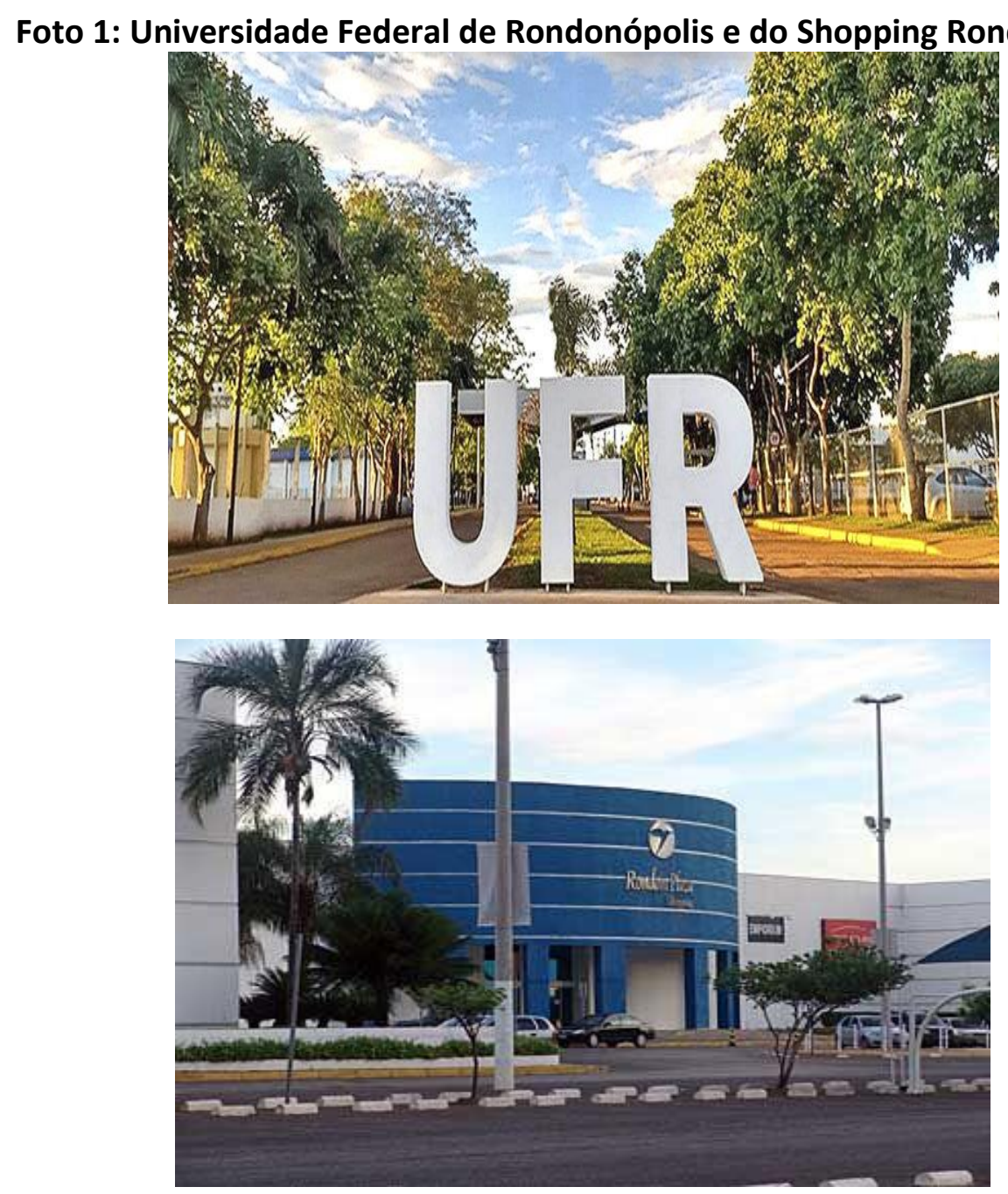

Fonte: Org. TRINDADE, Adinael Jr. P. (2020)

A presença destes equipamentos promoveu a valorização do solo urbano estimulando

Bittencourt; Trindade; Nardes, Intervenção dos Agentes Imobiliários no Entorno Imediato das Centralidades de Rondonópolis-MT DOI: https://doi.org/10.51308/continentes.v1i18.296 
o surgimento de dois loteamentos abertos voltados a classe média e dois loteamentos fechados de alto padrão focados na classe média-alta e alta, além de diversos condomínios verticais.

Com o adensamento populacional ocorrido na última década na área em questão, notamos o crescimento do número de empresas voltadas ao comércio, restaurantes pubs e outros em praticamente toda a Avenida Júlio Campos e mais recentemente observamos o crescimento do número de edifícios residenciais na própria avenida e em seu entorno, constituindo a localidade em uma centralidade. Esses processos, ajudam a explicar a origem e a funções das centralidades presentes em Rondonópolis.

Podemos ainda observar a influência e a atuação dos agentes imobiliários que munidos de recursos políticos e financeiros são capazes de induzir o surgimento de uma centralidade, ainda que alguns casos se caracterizem por ser uma centralidade especializada na oferta de serviços específicos como o oferecimento de ensino superior na Universidade Federal de Rondonópolis (UFR), comércio de alimentos ou serviços médico-hospitalares como na Vila Birigui e Jardim Guanabara.

\section{Áreas de intervenção dos agentes imobiliários no entorno das centralidades}

As cidades de modo geral possuem uma estrutura de organização semelhante, com a evolução do tecido urbano a partir de um centro original que concentra os serviços públicos e o comércio (TRINDADE, 2017). Dessa forma, com a expansão da cidade abrese a possibilidade para o surgimento de centros secundários. Nesse sentido, as centralidades como verificamos é o produto, onde

Cada cidade brasileira tem geralmente, um centro principal no qual se localizam órgãos da administração pública, a igreja matriz, os tribunais, o distrito financeiro, o comércio atacadista, o comércio varejista de luxo, [...] etc. [...] Na medida que a cidade vai crescendo, centros secundários de serviços vão surgindo em bairros, que formam novos focos de valorização do espaço urbano (SINGER, 1980: 84).

Bittencourt; Trindade; Nardes, Intervenção dos Agentes Imobiliários no Entorno Imediato das 
Nesse contexto, podemos afirmar que o processo de crescimento de Rondonópolis iniciado na década de 50 do século XX e intensificada a partir da década de 70 do mesmo século, com a introdução das culturas da soja e algodão desencadearam uma profunda reestruturação do tecido urbano local, com a incorporação de novas áreas e reconfiguração do centro primário cuja atividade principal passou a ser o comércio.

Tal processo, associado ao crescimento desordenado incorporaram grandes vazios ao tecido urbano que somados a falta de transporte público, certamente contribuiriam mesmo que de modo não intencional para o surgimento das diversas centralidades hoje existente em Rondonópolis.

Grosso modo, podemos afirmar que todas as regiões ou setores afastados geograficamente do centro primário possuem uma relativa atividade comercial já consolidada com objetivo de atender a demanda imediata dos moradores da região. Ressaltamos, que essas centralidades em geral, comerciais e de serviços não estabelecem uma relação de concorrência, mas de complementaridade com o centro primário.

Neste estudo, nos restringiremos a uma descrição de algumas áreas elencadas como centralidades e das atividades principais a elas relacionadas. Desde já, destacamos que tal escolha ocorreu de modo arbitrário a partir de nossa própria percepção de relevância e destaque dessas centralidades, o que não significa que negligenciamos a existência de outras localidades na cidade que desempenhem em alguma medida a função de centralidade, mas que por uma questão de delimitação espacial de nosso objeto de estudo não são consideradas nessa pesquisa.

Nesta pesquisa, assumimos que a especulação imobiliária ocorre em função de relação de oferta e demanda além do crescente interesse de pessoas físicas, empresas públicas e privadas de economia mista, imobiliárias e outros, em adquirir bens imóveis com o intuito de especular e posteriormente com o aumento artificial do imóvel ou terreno obter lucro por meio da venda ou aluguel. Conforme descreve CORRÊA (1989: 20), 
quando destaca que objetivo dos promotores imobiliários é "comercialização ou transformação do capital-mercadoria em capital-dinheiro, agora acrescido de lucro."

Considerando essa premissa, CAMPOS FILHO (2001: 48) menciona que a especulação imobiliária é "uma forma pela qual os proprietários de terras recebem uma renda transferida dos outros setores produtivos [...], especialmente através de investimentos públicos na infraestrutura e serviços urbanos." Nesse sentido, devido a região que o imóvel ocupa não dispor de infraestrutura, o empreendedor consegue comprá-lo por um preço relativamente baixo e posteriormente espera a intervenção pública que trará para aquele local a infraestrutura e serviços urbanos necessários.

A partir da intervenção do agente público, ocorre uma valorização do imóvel possibilitando ao proprietário vendê-lo ou alugá-lo por um preço superior ao que havia comprado/investido e sem contribuição ao governo, ou seja, gerando ao proprietário lucros sem necessariamente realizar nenhum investimento próprio.

Ao interferir em uma área trazendo benfeitorias, o agente público torna aquele local valorizado, dando abertura para os promotores imobiliários investirem nos espaços vazios, de modo que terrenos e/ou imóveis também sofrerão elevação dos preços se tornando lucrativos a longo prazo.

Corroborando com CAMPOS FILHO (2001), NOGUEIRA e GODÓI (2012: 13) salientam que a especulação imobiliária torna-se:

Um fenômeno inerente ao contexto de expansão das grandes cidades. Portanto, ela manifesta-se precipuamente nas áreas em que há densa concentração populacional. E, na maioria dos casos, é reflexo das manifestações e contradições oriundas da expansão desordenada dos perímetros urbanos.

Nessa perspectiva, segundo os autores, existe uma ligação intrínseca entre a expansão das grandes cidades e a especulação imobiliária, ocorrendo com mais frequência em locais com maior população. Tal fato, pode ser proveniente do crescimento desordenado das cidades.

Bittencourt; Trindade; Nardes, Intervenção dos Agentes Imobiliários no Entorno Imediato das Centralidades de Rondonópolis-MT DOI: https://doi.org/10.51308/continentes.v1i18.296 
Ainda sobre o assunto, SANTOS (2008: 106) apresenta uma outra visão. Segundo ele, a especulação imobiliária "deriva [...] da conjugação de dois movimentos convergentes: a superposição de um sítio social ao sítio natural e a disputa entre atividades ou pessoas por dada localização. A especulação se alimenta dessa dinâmica, que inclui expectativas."

A conceituação proposta por SANTOS (2008), pode ser observada em áreas específicas do recorte geográfico da pesquisa, principalmente na avenida Júlio Campos, onde o setor de serviços vem se desenvolvendo com grande velocidade, gerando enorme pressão sobre os preços dos imóveis territoriais e prediais na região.

A partir dos aportes apresentados por SANTOS (2008), NOGUEIRA e GODÓI (2012), podemos inferir que a especulação imobiliária é um fenômeno social desencadeado por um crescente interesse social de indivíduos e organizações em determinada área. Nessa acepção, "uma especulação não se consuma apenas por um grupo delimitado de sujeitos, um grupo de oportunistas. Pelo contrário, a especulação, via de regra, atinge e move-se sob responsabilidade da sociedade como um todo" (NOGUEIRA; GODÓI (2012: 10).

Por meio dessas constatações, foi possível identificar alguns dos elementos e agentes que compõem esses fenômenos dos quais destacamos: área geográfica de interesse, centralidades e agentes imobiliários públicos e privados tais como os proprietários fundiários, promotores imobiliários, grupos sociais excluídos, além do próprio Estado.

\section{Vila Operária}

Resultante do processo de crescimento experimentado por Rondonópolis a partir dos anos de 1950, Vila Operária é "o primeiro loteamento implantado em Rondonópolis, após a emancipação político-administrativa, abrangendo área inicial de 30 hectares" (DEMAMANN, 2011: 47).

Bittencourt; Trindade; Nardes, Intervenção dos Agentes Imobiliários no Entorno Imediato das Centralidades de Rondonópolis-MT DOI: https://doi.org/10.51308/continentes.v1i18.296 
Segundo SUZUKI (1996), apesar de a ampliação do tecido urbano ter se iniciado em 1950, por Domingos de Lima, somente após a nomeação do prefeito Daniel Martins de Moura é que a criação do loteamento da Vila Operária ocorreu de fato. Tal criação, teve início depois que o então prefeito Moura doou terrenos para que fosse criado o loteamento. O mesmo o nomeou de Distrito de Vila Operária de São José. Após sua criação, foi loteado e "doados às pessoas de baixa renda, para que estas, ao construírem suas casas, pudessem receber o título definitivo de proprietário" (DEMAMANN, 2011: 47).

DEMAMANN (2011: 48), complementa argumentando que "a Vila Operária abrigava os migrantes de baixo poder aquisitivo que chegavam a Rondonópolis, e foi tornando-se um centro comercial periférico de pequeno comércio, servindo as áreas próximas, podendo ser considerado um prolongamento do centro maior." Desde então, vem crescendo, chegando a se tornar um segundo centro, ou melhor, como denominado por DEMAMANN (2011) um "subcentro" da cidade de Rondonópolis.

Ainda segundo DEMAMANN (2011: 167), o bairro Vila Operária detém uma elevada "densidade demográfica, o que cria demandas por bens e serviços. E isso tem sido determinante para o desenvolvimento socioeconômico do local, com diversificação de comércios e serviços para atender a população do entorno do subcentro". O mosaico a seguir (Foto 2), apresenta uma comparação entre o centro principal (nas primeiras imagens) com "centro" de Vila Operária (três últimas), na imagem podemos observar uma amostra do comércio de vila Operária, bem como sua semelhança com encontrado no centro principal da cidade de Rondonópolis.

Bittencourt; Trindade; Nardes, Intervenção dos Agentes Imobiliários no Entorno Imediato das Centralidades de Rondonópolis-MT DOI: https://doi.org/10.51308/continentes.v1i18.296 
Foto 2: Região central de da Vila Operária e o centro principal de Rondonópolis
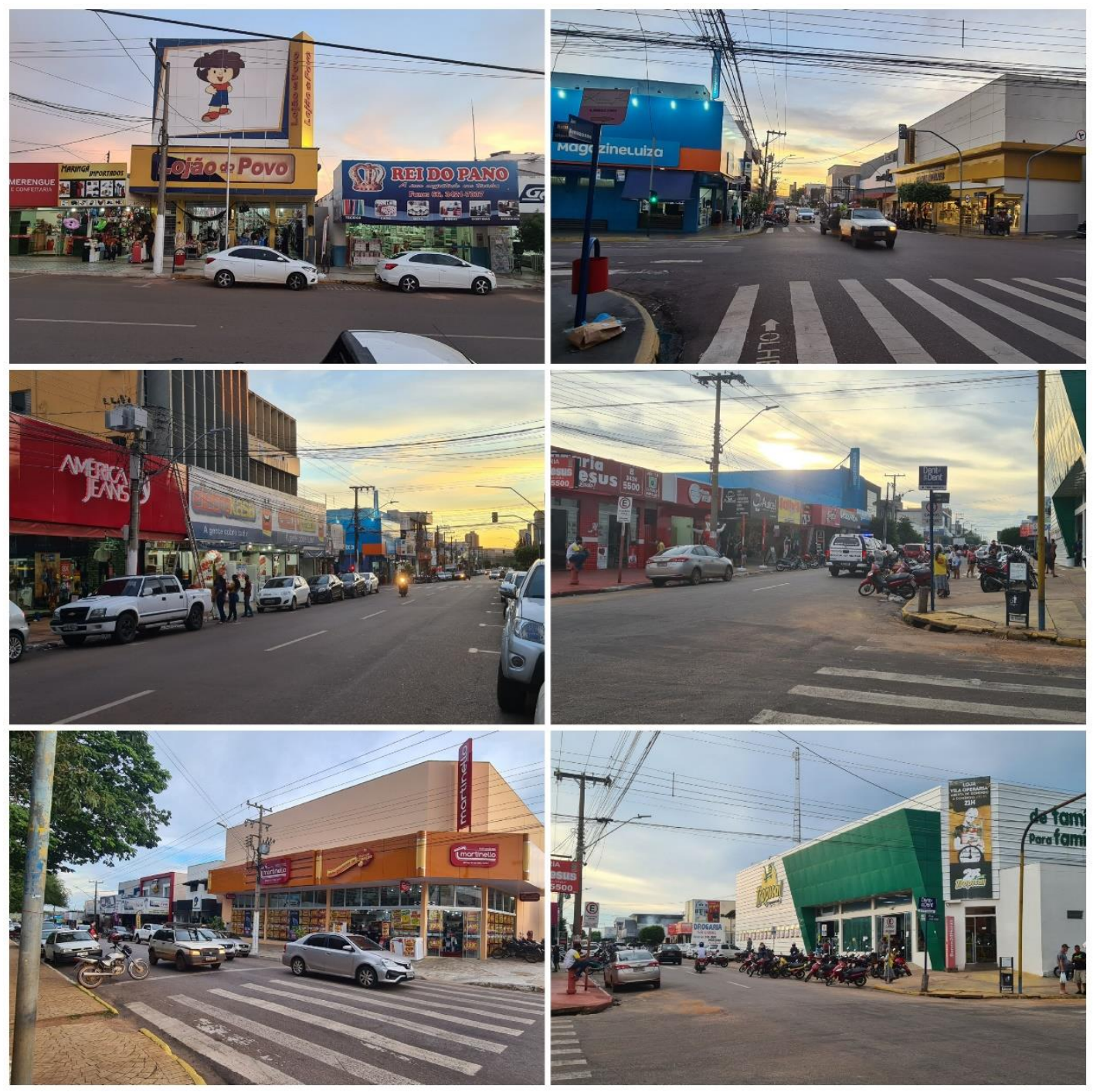

Fonte: Org. TRINDADE, Adinael Jr. P. (2020)

Podemos afirmar, que a região central da Vila Operária e o centro principal de Rondonópolis são em certa medida, (observada as devidas proporções) semelhantes pelas características que servem, embora o centro da cidade possua uma oferta maior de serviços e sua atividade comercial seja mais intensa, a centralidade de Vila Operária possui lojas de departamentos, vestuários, farmácias, supermercados e até cartório. 


\section{Universidade Federal de Rondonópolis (UFR)}

\section{Mapa 2: Centralidade - Av. Julio Campos/UFR}

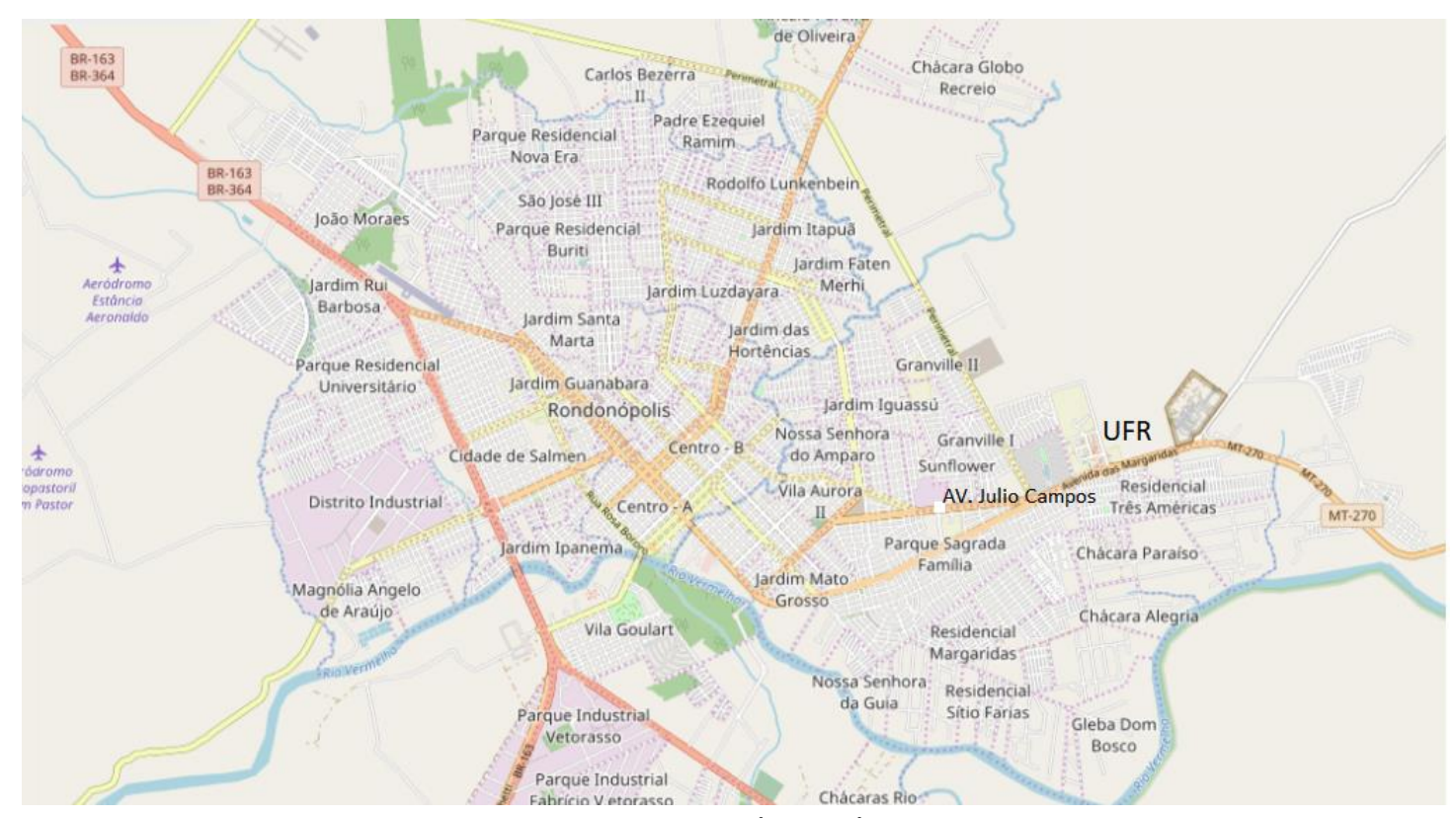

Fonte: Google Earth

Org. TRINDADE, Adinael Jr. P. (2020)

Outro agente indutor de uma centralidade é a Universidade Federal de Rondonópolis (UFR). O Campus Universitário de Rondonópolis teve seu início com a implantação de cursos de ensino superior em 1976, ofertados pela Universidade Estadual, sediado em Campo Grande, atualmente Mato Grosso do Sul. Inicialmente o campus ofertava principalmente cursos de licenciatura-curta na área de Ciências Exatas e Estudos Sociais. Localizada na hoje denominada Avenida dos Estudantes (nome dado em homenagem a UFR), a universidade foi instalada distante do centro da cidade em uma área que outrora havia sido uma plantação de arroz, de modo que a instalação do então campus universitário fora pensada com parte de uma estratégia de valorização do entorno para fins de exploração imobiliária através da venda de terrenos, uma vez que na época a 
universidade encontrava-se afastada do tecido urbano, localizando-se as margens da MT 270 ( $k m$ 06), como observado na Foto 3.

\section{Foto 3: CPR em 1981}

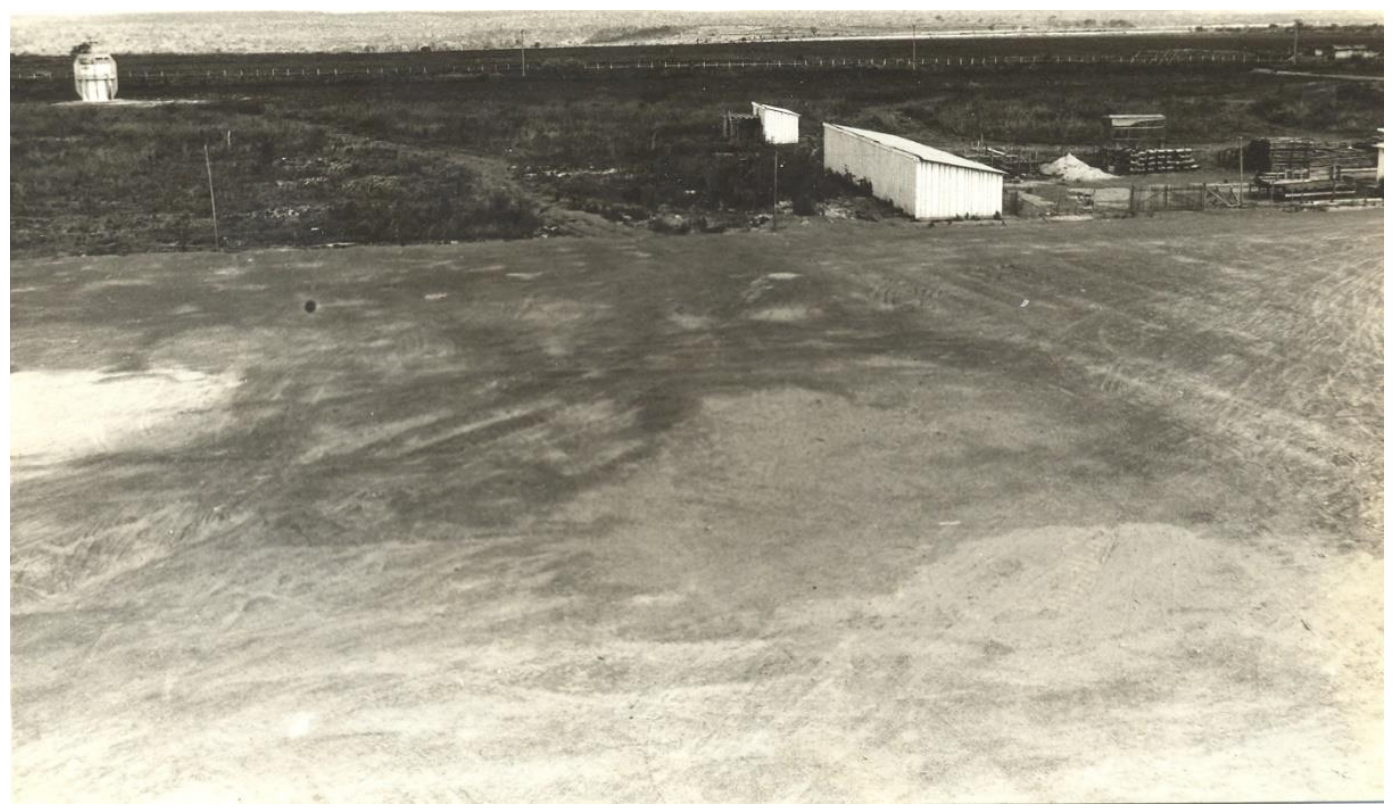

Fonte: Arquivo Universidade Federal de Rondonópolis.

A partir da divisão do Estado de Mato Grosso para criação do Estado de Mato Grosso do Sul, o Campus Universitário, então centro pedagógico foi vinculado a Universidade Federal de Mato Grosso, sediada em Cuiabá.

A construção da sede própria cujo aconteceu após um longo processo de reivindicações junto às instâncias superiores da UFMT, tendo sido a área doada pelo Sr. Áureo Candido que dentre as motivações vislumbrou a possibilidade de valorização de suas propriedades fundiárias. Atualmente essa centralidade tem como característica principal o oferecimento de serviço educacional público superior. Ela é um centro de 
interesse regional, visto que muitas pessoas vêm de outras cidades para estudar na instituição.

A Universidade Federal também favoreceu o incremento dos serviços ligados a locação/hospedaria e alimentícios, principalmente nos bairros Atlântico e Europa. Tais bairros, juntamente aos bairros mais próximos oferecem imóveis para aluguel como casas, quitinetes e apartamentos, além de serviços voltados ao ramo alimentícios.

"a cidade, que se forma a partir de agrupamento rural, adquire um novo papel no cenário regional a partir da reorganização do Estado de Mato Grosso pós divisão

Em torno dessa centralidade, também está localizada dois loteamentos fechados de alto padrão, Village do Cerrado e Royal Boulevard do Cerrado, bem como dois loteamentos de classe média, GranVille e Sunflower.

(criação de Mato Grosso do Sul em 1977), quando a cidade foi transformada em polo industrial e comercial até alcançar o status atual de polo Considerados condomínios de luxo, o Royal regional de serviços". Boulevard do Cerrado e Village do Cerrado são empreendimentos relativamente novos, construídos entre 2010 e 2015 . Os valores dos terrenos e casas nesses condomínios são bem elevados, principalmente no Village do Cerrado. Acreditamos que o preço é mais elevado em virtude da consolidação do condomínio.

Nesse sentido, a Tabela 1 apresenta uma amostra dos preços praticados na cidade, e tem por objetivo ilustrar as diferenças nos valores praticados em Rondonópolis, a depender da localidade em que se situa o imóvel em questão. 
Tabela: Amostra dos preços praticados na cidade de Rondonópolis.

\begin{tabular}{|c|c|c|c|}
\hline Localização & $\begin{array}{c}\text { Valor de } \\
\text { venda }\end{array}$ & $\begin{array}{c}\text { Tamanho do } \\
\text { terreno }\end{array}$ & Venda por $\mathbf{m}^{\mathbf{2}}$ \\
\hline Vila Mineira & $\mathrm{R} \$ 55.000$ & $330 \mathrm{~m}^{2}$ & $\mathrm{R} \$ 166,67$ \\
\hline Vila Aurora & $\mathrm{R} \$ 320.000$ & $600 \mathrm{~m}^{2}$ & $\mathrm{R} \$ 533,33$ \\
\hline Granville I & $\mathrm{R} \$ 380.000,00$ & $740,00 \mathrm{~m}^{2}$ & $\mathrm{R} \$ 513,51$ \\
\hline Vila Birigui & $\mathrm{R} \$ 220.000,00$ & $360,00 \mathrm{~m}^{2}$ & $\mathrm{R} \$ 611,11$ \\
\hline $\begin{array}{c}\text { Santa Cruz } \\
\text { Vila Operária }\end{array}$ & $100.000,00$ & $100,00 \mathrm{~m}^{2}$ & $\mathrm{R} \$ 1.000,00$ \\
\hline Jardim Sunflower & $\mathrm{R} \$ 195.000,00$ & $580,00 \mathrm{~m}^{2}$ & $\mathrm{R} \$ 336,21$ \\
\hline Pq. São Jorge & $\mathrm{R} \$ 105.000$ & $360 \mathrm{~m}^{2}$ & $\mathrm{R} \$ 291,67$ \\
\hline Royal Boulevard do \\
Cerrado & 245.000 & $380 \mathrm{~m}^{2}$ & $\mathrm{R} \$ 644,73$ \\
\hline
\end{tabular}

Fonte: Org. BITTENCOURT, A. C. R.

Nota-se que os valores mais baixos são os praticados nos conjuntos habitacionais, que uma vez implantados também favorecem a valorização de áreas intermediárias, localizada entre esses e as áreas "centrais", uma vez que a essas áreas recebem infraestrutura (rede de água e esgoto, iluminação pública, transporte urbano etc.), gerando a discrepância como observado na Tabela.

A Avenida Júlio Campos e a Avenida Brasil tornaram-se centralidades posteriormente a construção do Rondon Plaza Shopping, principal agente indutor daquela centralidade. Nesse sentido, NARDES (1997: 136) menciona que a construção do shopping corroborou para a ocorrência da "especulação imobiliária [no] seu entorno e a cristalização 
contemporânea de comércio e lazer." Corroborando o posicionamento, DEMAMANN (2011: 138), afirma que

atualmente, o empreendimento é uma centralidade seletiva que se consolida na cidade. A concentração de comércios e serviços no Rondon Plaza Shopping garante a especialização da centralidade. Somadas as intensas transformações socioespaciais no seu entorno, nos últimos anos, o processo de verticalização fez surgir os edifícios de uso residencial [...] aproveitando o solo altamente valorizado.

As avenidas supracitadas concentram atividades comerciais ligadas a diversos setores como bancos, hospitais veterinários, atividades de lazer, alimentação e outros. Nos últimos anos, porém, a avenida Júlio Campos tornou-se um espaço recorrente de intervenções de agentes imobiliários.

A exemplo disso, são as construções de grandes edifícios verticais, entre eles, está o "Splendore" que encontra-se em fase inicial de construção e possuirá quarenta e um andares tornando-se segundo seus idealizadores o mais alto edifício do estado.

Ainda na avenida Júlio Campos, temos também o edifício Granlux em fase final de construção, atualmente o mais alto de Rondonópolis com trinta e um andares, figurando entre os mais altos do estado. Como afirmamos, a Avenida Júlio Campos tem vivenciado um acelerado processo de valorização, despertando o interesse de diversos agentes, dentre eles os ligados a exploração imobiliária.

Nesse sentido, observamos a expansão dos edifícios residenciais na referida avenida nos últimos anos chegando a três grandes empreendimentos, instalados diretamente neste logradouro. Porém, se expandirmos o recorte para ruas e avenidas subjacentes, esse número sobe para cinco grandes empreendimentos, mesmo desconsiderando edificações com menos de dez pavimentos. Na foto 4 mostra alguns desses empreendimentos.

Bittencourt; Trindade; Nardes, Intervenção dos Agentes Imobiliários no Entorno Imediato das 


\section{Foto 4 - Edifícios residenciais}

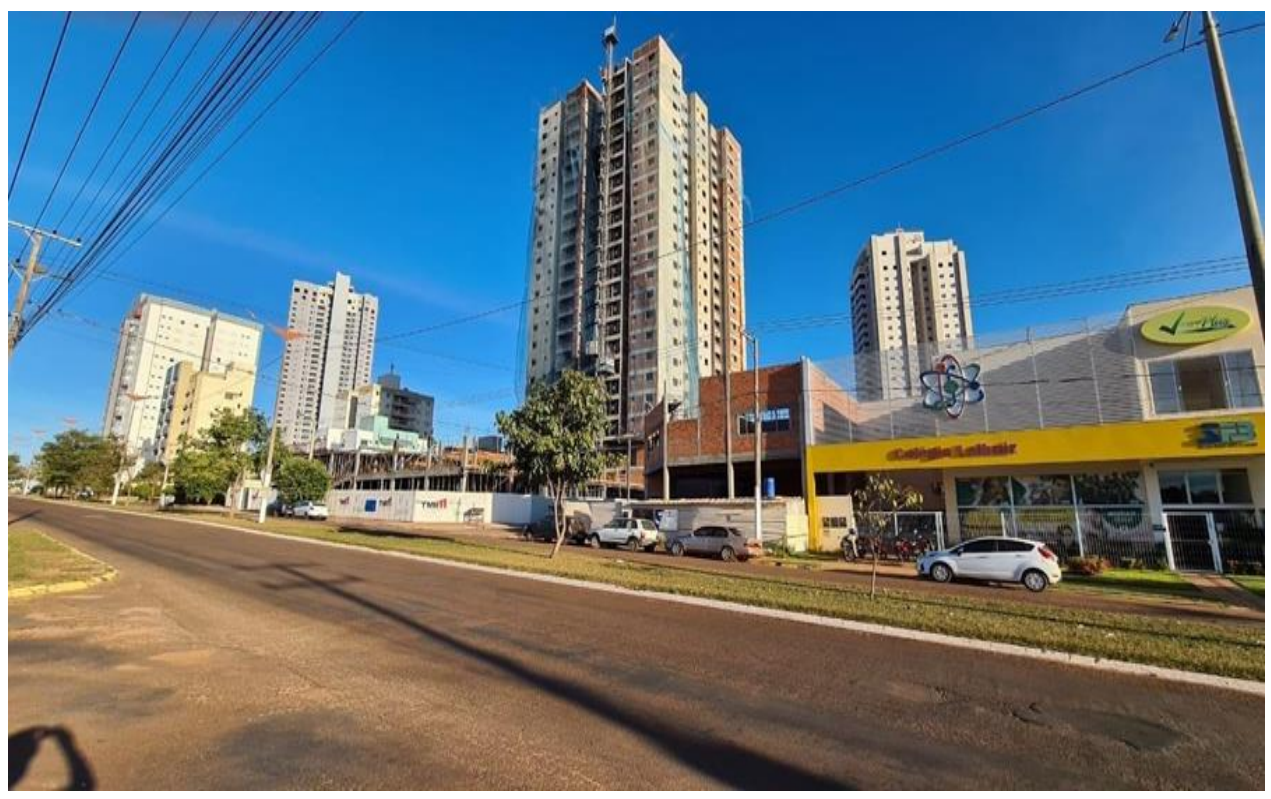

Fonte: BITTENCOURT, Ana Claudia R. (2020)

Um aspecto importante a ser considerado, é que com a consolidação desses empreendimentos, essas áreas tem se tornado uma das mais valorizadas da cidade, o que favorece o processo de verticalização como forma atuação dos agentes imobiliários, no que compete a exploração do solo urbano.

\section{Considerações Finais}

A presente pesquisa permitiu lançar um novo olhar sobre a expansão da cidade de Rondonópolis. Embora as áreas analisadas não sejam necessariamente "novas" quanto sua integração a malha urbana, essas áreas têm desempenhado diferentes papéis e funções quanto a seus usos e sua ligação com o modo de exploração capitalista do solo urbano.

É importante frisar que o observado em Rondonópolis/MT é resultante de um processo de décadas pelo qual a cidade assumiu a sua conformação atual, (porém nunca acabada). Nesse processo, a cidade, que se forma a partir de agrupamento rural, adquire um novo papel no cenário regional a partir da reorganização do Estado de Mato Grosso 
pós divisão (criação de Mato Grosso do Sul em 1977), quando a cidade foi transformada em polo industrial e comercial até alcançar o status atual de polo regional de serviços.

No que tange as centralidades, CASTELLS (1983: 321) afirma que "a desconcentração da função comercial conduz à criação de centros-de-troca periféricos, servindo às áreas urbanas determinadas, ou aproveitando-se de uma situação na rede de fluxos cotidianos na metrópole." Nesse sentido, com a crescente expansão da malha urbana, ocorre a descentralização do centro, nascendo novos centros de comércio que servem áreas específicas.

Assim através deste estudo, pudemos analisar o processo de exploração capitalista da cidade, bem como a ação de diversos agentes imobiliários e sua relação com as centralidades urbanas, verificando que tipo o de intervenção adotado considera diversos fatores na sua consolidação.

\section{Referências Bibliográficas}

ANGEOLETO, Fábio. (2017). Localização de Rondonópolis [formato]. Escala 1:100. [Consultado em 08 de março] 2021, [Researchgate.]. [Website:] tps://www.researchgate.net/figure/Figura-1-Localizacao-de-RondonopolisMT_fig1_318781592.

CAMPOS, Heleniza Ávila; SILVEIRA, Rogério Leandro Lima da. (org.). Valorização do solo e reestruturação urbana: os novos produtos imobiliários na Região de ValesRS. Santa Cruz do Sul. EDUNISC, 2014. Disponível em: http://unisc.br/editora/e_book_valorizacao_do_solo.pdf. Acesso em: 08 ago. 2020.

CAPOS FILHO, Candido Malta. Cidades brasileiras: seu controle ou caos. 4. ed. São Paulo: Studio Nobel, 2001.

CASTELLS, Manuel. A questão urbana. Rio de Janeiro: Paz e Terra, 1983.

CORRÊA, Roberto Lobato. O espaço urbano. 4. ed. 5. reimp. São Paulo: Ática, 2004.

DEMAMANN, Mirian Terezinha Mundt. Rondonópolis-MT: campo, cidade $e$ centralidades. 2011. 250f. Tese (Doutorado em Geografia) - Universidade de São Paulo, São Paulo, 2011. Disponível em: 
https://teses.usp.br/index.php?option=com_jumi\&fileid=17\&ltemid=160\&id=E7 A2296 701CE\&lang=pt-br. Acesso em: 01 dez. 2019.

MOTTER, Crislaine; BATELLA, Wagner. Novas centralidades em Chapecó: apontamentos sobre as transformações recentes no espaço urbano. Caminhos de Geograia, Uberlândia, MG, v. 14, n. 46, p. 60-70, jun. 2013. Disponível em: http://www.seer.ufu.br/index.php/caminhosdegeografia/. Acesso em: 20 jan. 2020.

NARDES, Antonia Marilia. Rondonópolis-MT: sua espacialidade reconstruída. 1997. 155 f. Dissertação (Mestrado em Geografia) - Universidade Federal de Brasília, Brasília, 1997.

NOGUEIRA, Roberto Henrique Pôrto; GODÓl, Nayder Rommel de Araújo. Para uma tentativa de reconstrução do conceito jurídico de especulação imobiliária. In: CONGRESSO NACIONAL DO CONPEDI/UFF, 21, Florianópolis, RJ, 2012. Anais... Florianópolis, RJ:FUNJAB,2012. Disponível em: http://www.publicadireito.com.br/publicacao/uff.php. Acesso em: 17 jul. 2020.

SANTOS, Milton. A urbanização brasileira. 5. Ed. São Paulo: Editora da Universidade de São Paulo, 2008.

SILVA, William Ribeiro da. A formação do centro principal de Londrina e o estudo da centralidade urbana. GEOGRAFIA, v. 12, n. 2, jul./dez. 2003. Disponível em http://www.geo.uel.br/revista. Acesso em: 08 mar. 2020.

SINGER, Paul. O uso do solo urbano na economia capitalista. In: MARICATO, Erminia (org.). A produção capitalista da casa (e da cidade) no Brasil industrial. São Paulo: ALFA-OMEGA, 1982.

SUZUKI, Júlio César. De povoado a Cidade: a transição do rual ao urbano em Rondonópolis. 1996. 238 f. Tese (Doutorado em Geografia) - Universidade de São Paulo, São Paulo, 1996. Disponível em: https://repositorio.usp.br/single.php?_id=000746445. Acesso em: 25 jun. 2020.

TRINDADE, Adinael Junhor Pereira da. Guiratinga/MT: do brilho a opacidade. 2017. 129 f. Dissertação (Mestrado em Geografia) - Universidade Federal de Mato Grosso, Rondonópolis, 2017.

SANTOS, M. Por uma Geografia Nova. São Paulo: Hucitec, Edusp, 1978.

Data de Submissão: $13 / 08 / 2020$

Data de Aceite: 24/05/2021

Bittencourt; Trindade; Nardes, Intervenção dos Agentes Imobiliários no Entorno Imediato das

Centralidades de Rondonópolis-MT

DOI: https://doi.org/10.51308/continentes.v1i18.296 